\title{
Emergence of rotavirus G9 in 2012, as the dominant genotype in Turkish children with diarrhea, in a university hospital in Ankara
}

\author{
Aylin Altay Koçak ${ }^{1}$, Merve Aydın², Takashi Matsumoto ${ }^{3}$, Takaaki Yahiro ${ }^{4}$, Buket \\ Dalgıç ${ }^{5}$, Gulendam Bozdayi ${ }^{6 *}$, Kamruddin Ahmed ${ }^{7}$
}

1. Department of Medical Microbiology, Gazi University Faculty of Medicine, Ankara, Turkey; Department of Medical Microbiology, Baskent University Faculty of Medicine, Ankara, Turkey 2. Department of Medical Microbiology, Erzincan University Faculty of Medicine, Erzincan, Turkey; Department of Medical Microbiology, KTO Karatay University Faculty of Medicine, Konya, Turkey

3. Department of Microbiology, Oita University Faculty of Medicine, Oita, Japan

4. Department of Pathobiology and Medical Diagnostics, University Malaysia Sabah Faculty of Medicine and Health Sciences, Kota Kinabalu, Malaysia

5. Department of Pediatric Gastroenterology, Gazi University Faculty of Medicine, Ankara, Turkey

6. Department of Medical Microbiology, Gazi University Faculty of Medicine, Ankara, Turkey

7. Borneo Medical and Health Research Centre, University Malaysia Sabah Faculty of Medicine and Health Sciences, Kota Kinabalu, Malaysia

\begin{abstract}
Introduction: Rotavirus infection is a major cause of morbidity and mortality in infants and young children with diarrhea throughout the world. Material and Methods: In this study, we aimed to determine the detection rate of rotavirus infection in 181 children less than 5 years of age presenting with acute gastroenteritis and admitted to a tertiary care hospital in Ankara, Turkey, from April to November 2012. We documented the epidemiological data by elucidating the prevalent genotypes. Stool specimens were collected, and rotavirus antigen in the samples was detected using ELISA. G and P genotypes were determined by RT-PCR via type specific primers. The nucleotide sequence of the concerned genes was determined by Sanger sequencing and phylogenetic analysis was performed by neighbor-joining method. Results: Of the 181 samples, 28 (15.5\%) were positive for the rotavirus antigen. Twenty-seven samples were positive for G genotypes and 21 were positive for P genotypes. Genotypes G1 (7.1\%), G2 (7.1\%), G3 (7.1\%), G4 (3.6\%), G9 (71.5\%) and P4 (3.6\%), P8 (71.4\%) were identified. Genotype G9P[8] (50\%) was predominant in the combination of $G$ and $P$ genotypes. Most of the $G 9$ strains of this study formed an independent cluster in Lineage III, except two strains which clustered with an Ethiopian G9 strain of 2012. Conclusions: It seems that during 2012 season, genotype G9P[8] increased significantly in Ankara due to a new circulating strain of $G 9$.
\end{abstract}

Keywords: children, genotype, rotavirus infection, Turkey

Received: $5^{\text {th }}$ November 2018; Accepted: 16 ${ }^{\text {th }}$ March 2019; Published: $4^{\text {th }}$ April 2019

*Corresponding author: Gulendam Bozdayi, Gazi University, Faculty of Medicine Ankara, Turkey.

E-mail: gbozdayi@hotmail.com 


\section{Introduction}

Globally, diarrhea remains the second most common cause of death among children under five years of age $(1,2)$. In Turkey, every year, there are 1.25 million births and the annual number of diarrhea episodes in children under five is estimated to be 13,371,800 (3). Rotavirus (RV) is the most significant cause of severe gastroenteritis in children of the age group mentioned before. The latest WHO estimate of rotavirus deaths every year around the world declined from 453,000 in 2008 to 215,000 in $2013(4,5)$.

$\mathrm{RV}$ is a non-enveloped, double-stranded (ds) RNA virus belonging to the Reoviridae family. The RV genome consists of 11 dsRNA segments and encodes six structural proteins (VP1-4, VP6, and VP7) and 6 non-structural proteins (NSP1-6) (6). According to the classification system based on the gene sequence of VP6, an inner capsid protein, RVs are currently categorized into ten groups (A, B, C, D, E, F, G, H, I and J). Most RV infections in humans are caused by the Group $A$ RV $(6,7)$. Outer capsid proteins, VP7 (glycoprotein) and VP4 (protease-sensitive protein) respectively determine the $\mathrm{G}$ and $\mathrm{P}$ genotypes. To date, at least $36 \mathrm{G}$-genotypes and $51 \mathrm{P}$-genotypes have been identified in humans and other animals according to the last release of the Rotavirus Classification Working Group $(8,9)$.

$\mathrm{RV}$ genotypes that cause the majority of infections worldwide are G1P[8], G2P[4], G3P[8], G4P[8], and G9P [8] (10). First discovered in 1995, the G9 genotype occured all over the world and became the fifth most commonly detected human RV (10). Furthermore, G9 frequency has increased of late, and it is the predominant genotype found in recent studies conducted in Turkey $(11,12)$.

In Turkey, RV vaccination is currently not included in the national immunization program. Surveys on the prevalence of RV in Turkey show that the responsible genotypes vary considerably according to the year and the studied groups (13-15).
Therefore, it is necessary to identify the RV genotypes circulating in Turkey before including them in the national vaccination program. Moreover, the growing divergence of RVs and the emergence of G9 strains emphasize the need for continued RV surveillance in Turkey. In this study, we attempted to determine the detection rate of G9 genotype in Turkish children with acute gastroenteritis admitted to a tertiary care hospital in Ankara.

\section{Material and Methods}

\section{Collection of Stool Samples}

Stool samples were collected prospectively from 181 children (younger than 5 years of age) with acute gastroenteritis admitted to the Gazi University Hospital, Ankara, Turkey, from April to November 2012. The samples were sent to microbiology laboratories from various pediatric clinics. The samples were first examined routinely using the native-lugol method for screening of leucocytes, erythrocytes, and parasites. After the samples with leukocytes, erythrocytes, and parasites were excluded, the stool samples were stored in different aliquotes at $-80{ }^{\circ} \mathrm{C}$ for $\mathrm{RV}$ detection.

\section{Ethical Approvement}

This study was approved by the Ethics Committee of the Gazi University Ethics Committee (2010/01-152). Informed consent was obtained from the child's guardian prior to sample collection.

\section{Detection of RV Antigen (Ag) in Stool Samples}

The samples were diluted to $10 \%$ in phosphate-buffered saline, and RV group A antigen was identified using a commercially available ELISA kit (Rotaclone, Meridian Diagnostics Inc., Cincinnati, Ohio, USA) according to the manufacturer's instructions. Spectrophotometry was used to measure the optical density (OD) 
of the ELISA microplate at $450 \mathrm{~nm}$. The cut-off value was set at 0.150 , and if the OD of the sample was equal to or higher than the cutoff value, then the sample was designated as positive, and negative if the OD was lower.

\section{Extraction of dsRNA}

RV genomic dsRNA was extracted from the ELISA-positive samples by using a commercial kit (QIAamp Viral RNA Mini Kit, Qiagen, Germany) using the manufacturer's instructions.

\section{VP7 and VP4 Amplification via RT-PCR}

For VP7 and VP4 gene amplification, extracted RNA was transcribed to cDNA using AccessQuick $^{\mathrm{TM}}$ RT-PCR kit (Promega Corporation, Madison, WI, USA) and consensus primers Beg9 and End9 for VP7 gene, consensus primers con-2 and con-3 for VP4 gene $(16,17)$. The primer sets used for PCRs are listed in Table 1. RT-PCR was performed in a $50 \mu$ l volume: $1 \mathrm{X}$
Master Mix, $1 \mu \mathrm{M}$ concentrations of primers, $5 \mathrm{U}$ reverse transcriptase and $2 \mathrm{pg}$ of template RNA. RT-PCR for VP7 and VP4 amplification was carried out in a Thermal Cycler (ThermoHybaid PCR Px2, England) with the following conditions, respectively: reverse transcription of VP7 gene for $45 \mathrm{~min}$ at $45^{\circ} \mathrm{C}, 2 \mathrm{~min}$ at $95^{\circ} \mathrm{C}, 1$ $\min$ at $50^{\circ} \mathrm{C}, 1.5 \mathrm{~min}$ at $72^{\circ} \mathrm{C} ; 39$ cycles of $94^{\circ} \mathrm{C}$ for $1 \mathrm{~min}, 50^{\circ} \mathrm{C}$ for $1 \mathrm{~min}$, and $72^{\circ} \mathrm{C}$ for $1.5 \mathrm{~min}$; post-extension for $5 \mathrm{~min}$ at $72^{\circ} \mathrm{C}$; reverse transcription of VP4 gene for $45 \mathrm{~min}$ at $45^{\circ} \mathrm{C}, 2 \mathrm{~min}$ at $95^{\circ} \mathrm{C}, 30 \mathrm{~s}$ at $50^{\circ} \mathrm{C}, 1 \mathrm{~min}$ at $72^{\circ} \mathrm{C} ; 29$ cycles of $94^{\circ} \mathrm{C}$ for $15 \mathrm{~s}, 50^{\circ} \mathrm{C}$ for $30 \mathrm{~s}$, and $72^{\circ} \mathrm{C}$ for $1 \mathrm{~min}$; post-extension for $5 \mathrm{~min}$ at $72^{\circ} \mathrm{C}$.

\section{G and P Genotyping}

For $\mathrm{G}$ and $\mathrm{P}$ specific genotyping, PCR Master Mix (Promega Corporation, Madison, WI, USA) and primers for the most common genotypes were used. G genotyping was done by genotype specific primers for G1, G2, G3, G4, and G9. P

Table 1. $G$ and $P$ typing consensus and type-specific primers

\begin{tabular}{|c|c|c|c|}
\hline Primers & Sequences (5'-3') & Location (nt) & Amplicon Sizes (bp) \\
\hline \multicolumn{4}{|l|}{ G Typing } \\
\hline 1 st round consensus primers & & & 1062 \\
\hline Beg9 & GGCTTTAAAAGAGAGAATTTCCGTCTGG & $1-28$ & \\
\hline End9 & GGTCACATCATACAATTCTAATCTAAG & $1062-1036$ & \\
\hline \multicolumn{4}{|l|}{2 nd round } \\
\hline VP7-R & AACTTGCCACCATTTTTTCC & $914-932$ & - \\
\hline G1 & CAAGTACTCAAATCAATGATGG & $314-335$ & 618 \\
\hline $\mathrm{G} 2$ & CAATGATATTAACACATTTTCTGTG & $411-435$ & 521 \\
\hline G3 & ACGAACTCAACACGAGAGG & $250-269$ & 682 \\
\hline G4 & CGTTTCTGGTGAGGAGTTG & $480-498$ & 452 \\
\hline G9 & CTTGATGTGACTAYAAATAC & $757-776$ & 179 \\
\hline \multicolumn{4}{|l|}{ P Typing } \\
\hline 1 st round consensus primers & & & 887 \\
\hline Con2 & ATTTCGGACCATTTATAACC & $868-887$ & \\
\hline Con3 & TGGCTTCGCCATTTTATAGACA & $11-32$ & \\
\hline \multicolumn{4}{|l|}{2 nd round } \\
\hline HumCom5 & CTCTCGATGGTCCATATCAACC & $200-221$ & - \\
\hline $\mathrm{P}[4]$ & ATATATTGCCTATTTGTTTGAC & $347-368$ & 186 \\
\hline $\mathrm{P}[6]$ & GTATTACAGTTTCTACTTCAGA & $592-613$ & 381 \\
\hline $\mathrm{P}[8]$ & TGTACGTCTATTATAAAATTCATTT & $456-480$ & 280 \\
\hline $\mathrm{P}[9]$ & CGTCGCTCCTTGATACCAGT & $533-552$ & 350 \\
\hline
\end{tabular}


typing was done by genotype specific primers for $\mathrm{P}[8], \mathrm{P}[4], \mathrm{P}[6]$, and $\mathrm{P}[9]$ (Table 1) (17-20). PCR was performed in a $50 \mu 1$ volume: $1 \mathrm{X}$ Master Mix, $0.2 \mu \mathrm{M}$ concentrations of primers and 1 $\mu 1$ of template cDNA. PCRs for G and P genotyping were carried out with the following conditions, respectively: 30 cycles of $1 \mathrm{~min}$ at $95^{\circ} \mathrm{C}$, $2 \mathrm{~min}$ at $42^{\circ} \mathrm{C}, 1 \mathrm{~min}$ at $72^{\circ} \mathrm{C}$, post-extension for $5 \mathrm{~min}$ at $72^{\circ} \mathrm{C}$; and 30 cycles of $10 \mathrm{~s}$ at $94^{\circ} \mathrm{C}, 30$ $\mathrm{s}$ at $42^{\circ} \mathrm{C}, 30 \mathrm{~s}$ at $72^{\circ} \mathrm{C}$, post-extension for $5 \mathrm{~min}$ at $72^{\circ} \mathrm{C}$. Amplification products were analysed according to amplicon size in $2 \%$ agarose gel electrophoresis.

\section{Sequence Analysis for VP7 and VP4}

The nucleotide sequences of VP7 and VP4 genes were determined using BigDye terminator v3.1 cycle sequencing kit (Applied Biosystems, Foster City, CA, USA) according to the manufacturer's instructions, and the products were analyzed using the ABI Prism 3100 Genetic Analyzer (Applied Biosystems, Foster City, CA, USA).

\section{Phylogenetic Analysis}

Multiple sequence alignment was achieved using ClustalW algorithm belonging to BioEdit Sequence Alignment Editor version 7.1.3 as described by Hall TA (21), and phylogenetic anal- ysis was performed using MEGA 6 software and a distance based neighbour-joining method and Kimura's 2-parameter model (22).

\section{Results}

RV antigen was detected in $15.5 \%(28 / 181)$ of the samples as per ELISA. The age of the children ranged from 1 to 60 months, and the majority of RV infections were detected in children aged between 13 and 24 months $(28.6 \%)$, followed by $0-6$ month $(21.4 \%)$ old. The infection was lowest in children aged 37-48 months (3.6\%) (Figure 1).

The boys:girls ratio of RV-positive samples was 3:4. Sixteen (57.1\%) of the RV Ag-positive children were girls and 12 (42.9\%) were boys. Although the duration of our study did not include the entire year, RV was found to be mainly prevalent in April (33.3\%) and May (25.9\%). Thirteen samples were collected in June and 35 in November; however, they did not show positive results (Figure 2).

As a result of VP7 and VP4 amplification of 28 RV Ag-positive samples, G and P genotypes were detected in 27 and 21 samples, respectively. G9 (71.5\%; 20/28), G1 (7.1\%; 2/28), G2 (7.1\%; 2/28), G3 (7.1\%; 2/28), and G4 (3.6\%;

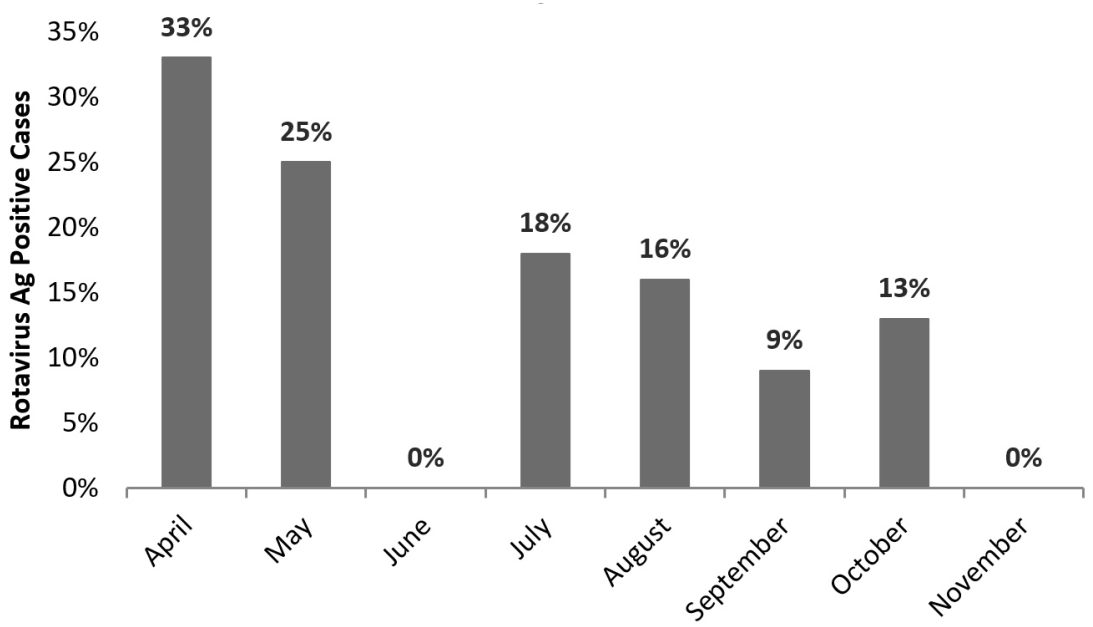

Fig. 1. The range of patients with rotavirus diarrhoea distributed according to age. 


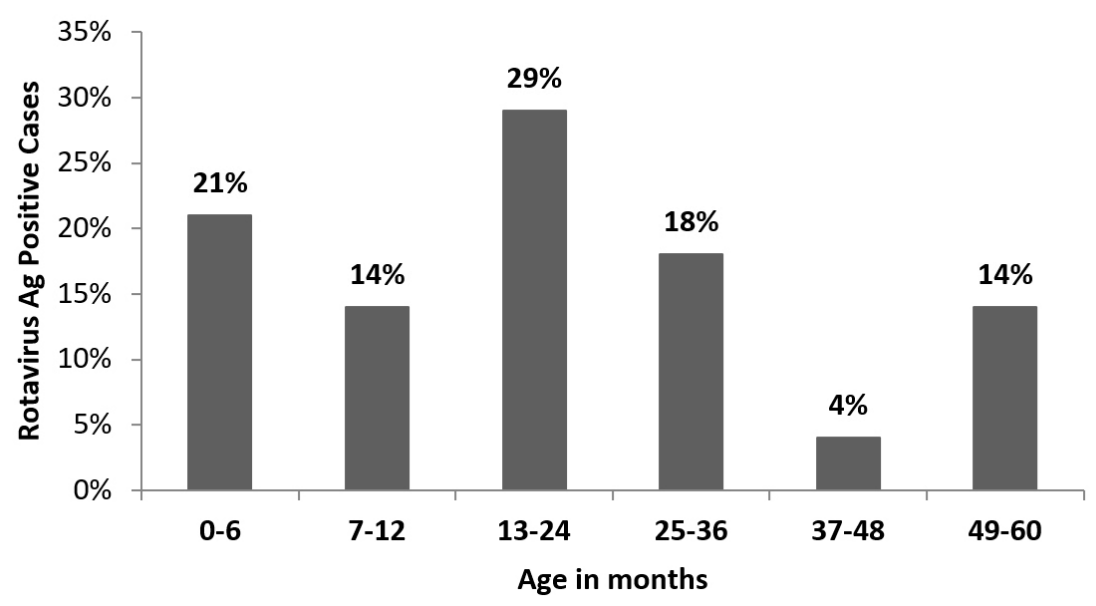

Fig. 2. The monthly occurrence of rotavirus diarrhoea among the children in Turkey. The monthly occurrence is represented by the percentage of rotavirus cases detected among the diarrheal cases of each month.

1/28) constituted the G genotypes; 3.6\% (1/28) of the samples, however, were untypable. $\mathrm{P}[8]$ $(71.4 \% ; 20 / 28)$ and $\mathrm{P}[4](3.6 \% ; 1 / 28)$ comprised the P genotypes; $25 \%$ (7/28) of the samples were untypable. Among the samples typed successfully, genotype G9P[8] (50\%) was predominant (Table 2).

G9-positive samples were then used for sequence analysis for phylogenetically analyzing the G9 strains. All the Turkish G9 strains belong to lineage III, and of the 13 G9 strains detected in this study, 11 formed an independent cluster. The other two strains formed a cluster with an Ethiopian G9 strain detected in 2012 (Figure 3).

\section{Discussion}

Our results showed that G9 and P[8] were the most common RV genotypes. Because the stool samples used in the present study belonged to 2012, an increase in G9 detection rate was expected. Following the implementation of RV vaccine worldwide, the prevalence of genotype G9 is increasing of late. Before 1990, G1P[8], G2P[4], G3P [8], and G4P[8] were the most common genotypes. Since then, however, G9P [8] has emerged as the fifth most common type around the world (23). This situation is similar to the genotype distribution in Turkey. G1P[8] tended to be the predominant genotype in earlier studies in Turkey $(13,14,24)$. Genotype G9, which is not included in the current vaccination program, started being detectable at very low frequencies in the late 1990s. It remains unclear whether widespread implementation of RV vaccines causes the emergence of non-vaccine genotypes. Recent regional epidemiological studies have confirmed the high prevalence of the genotype G9,

Table 2. Numbers and Percentages of Rotaviruses with Different G and P Types Combinations

\begin{tabular}{cccccccc}
\hline Genotypes & G1 & G2 & G3 & G4 & G9 & Gnt & Total \\
\hline $\mathrm{P}[4]$ & 0 & $1(3.6 \%)$ & 0 & 0 & 0 & $1(3.6 \%)$ & $2(7.1 \%)$ \\
\hline $\mathrm{P}[8]$ & $2(7.1 \%)$ & $1(3.6 \%)$ & $2(7.1 \%)$ & $1(3.6 \%)$ & $14(50 \%)$ & 0 & $20(71.5 \%)$ \\
\hline Pnt & 0 & 0 & 0 & 0 & $6(21.4 \%)$ & 0 & $6(21.4 \%)$ \\
\hline Total & $2(7.1 \%)$ & $2(7.1 \%)$ & $2(7.1 \%)$ & $1(3.6 \%)$ & $20(71.5 \%)$ & $1(3.6 \%)$ & $28(100 \%)$ \\
\hline
\end{tabular}




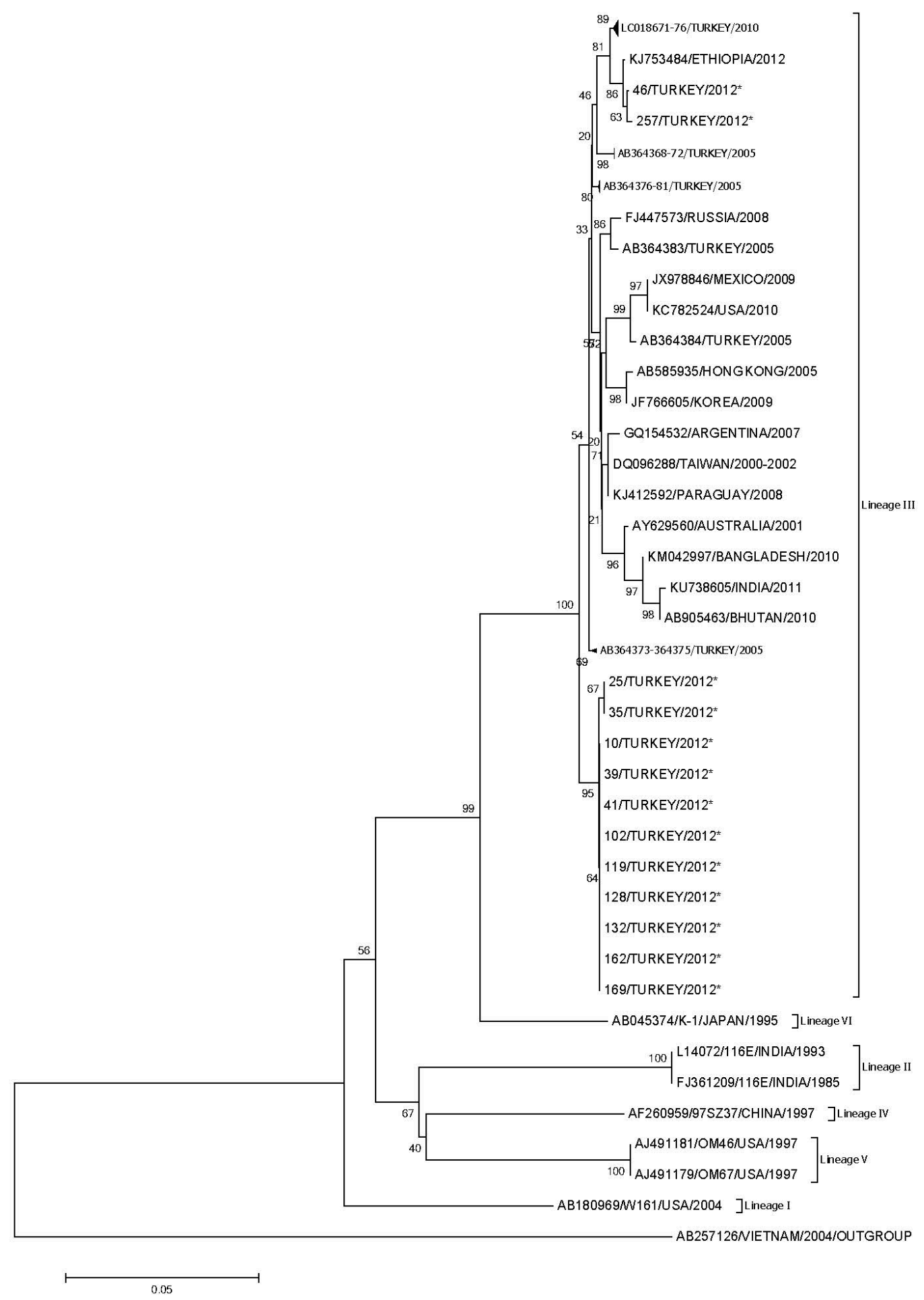

Fig. 3. The phylogenetic tree was constructed using the neighbour-joining method. Bootstrap analysis of 1,000 replicates was conducted to identify the significance of branching of the constructed tree. Bootstrap values of $>70$ are shown at branch nodes. Scale bar shows genetic distance expressed as nucleotide substitutions per site. 
reaching $50 \%-90 \%$ in some circumstances $(25)$. RV genotype diversity, especially that of G9 and G12, is a great challenge for current vaccination programs (11). Similar to our findings, low levels $(19.7 \%)$ of RV infection with higher proportion of G9 were detected in Argentina in 2005 (58.0\%) and 2006 (61.5\%) (26). In Denmark, G9 increase has been documented during 20092013 (27). Moreover, the emergence of G9 and G12 in 2010 in Bhutanese children has also been reported (28).

A Brazilian study (29) investigating changes in the epidemiology of RV during 2011-2012 found that after the monovalent RV vaccine was included in the national immunization program, RV was detectable in $1.7 \%(6 / 348)$ of the cases. RV positivity rates decreased to $88 \%$ in 2011 and $78 \%$ in 2012 compared with those in 2005/2006 (29). A study in Scotland found that the changing of the molecular epidemiology of RV infection after introduction of monovalent $\mathrm{RV}$ vaccination in 2012-2015. A decrease was seen in the prevalence of G1P[8] strains (from $72.1 \%$ to $15 \%$ ) after the introduction of the vaccine. Genotype G2P [4] was the predominant strain $(21.9 \%)$ with increase in G9P [8] (12.9\%) in 2013-2015 (30). In 2004, G9 emerged in Turkey and increased substantially in 2005 to $17.2 \%$ of the samples. Its frequency continued to increase, and it has since been confirmed to be the predominant genotype by recent studies. G9 was absent in the samples acquired from 2006 and 2007, but it then re-emerged in 2008 and increased gradually $(11,14)$. A pilot study showed that G9[P8] continued its dominance since 2008 as the primary genotype among children in Ankara. G9P[8] prevalence was $21.2 \%$ in 2008 , increasing to $34.8 \%$ in 2009 , $44.3 \%$ in $2010,40 \%$ in 2011 , and finally to over $70 \%$ of the strains including G9 (11). A previous study developed by "The Turkish rotavirus surveillance network" showed that during 20122014, genotype G9 was the most dominant genotype not only in Ankara but also all over Turkey, except the Eastern part (15). Another study in Central Anatolia (Afyon) revealed that G9P [8] (48.7\%) was the most common genotype during 2012-2013, followed by G9P[4] (17.5\%), similar to the findings of our study (31).

Currently, there are two oral, live attenuated RV vaccines: Rotarix (GlaxoSmithKline Biologicals, Rixensart, Belgium) and RotaTeq (Merck \& Co., Inc., Whitehouse Station, NJ, USA). The WHO has recently recommended the inclusion of rotavirus vaccination of infants in all national immunization programs (32). Although RV vaccines have not been introduced in the national vaccination programs in Turkey, both vaccines are commercially available (15). Following the implementation of the vaccination programs, some studies have reported an increase in genotype G9 prevalence in recent years. In 2009, Tapisiz et al. found in their study in Ankara that G9P [8] was the most frequently occurring genotype in 19 patients (19\%), followed by G1P[8] and G4P[6], each in 7 (7\%) patients (12).

In the present study, we found that the proportion of genotypes $\mathrm{G} 1, \mathrm{G} 2$, and G3 was $7.1 \%$ and that of G4 was $3.6 \%$. The total number of RV-positive samples was not high, and most of the positive samples belonged to genotype G9 (71.5\%). In the same geographic region, a similar study that included stool samples collected more recently (November 2016 and February 2018) from another tertiary care hospital which has lower income patient profile was conducted by Kahraman et al (33). Seventeen percent of 476 diarrheic stool samples were RV Ag positive. Genotype G1 (31\%) was the most prevalent genotype followed by G12 (20\%) and G9 was detected in $10 \%$. Although these results do not reflect the society incidence, a decrease can be seen in G9 frequency (33). Also a rotavirus surveillance study from Turkey in 2014-2016 reported that the most prevalent genotype was G1P[8] (24.6\%) followed by G3P[8] (19.6\%) and G9P[8] (12.2\%) (34). The samples of the 
present study belong to year 2012, which is one of the limitations of our study, however it can be seen from the literature that genotype G9 was the predominantly circulating genotype around 2012. Currently, G9 frequency is lower, but still circulating. Therefore, our results are important in terms of showing the predominance of G9 in 2012. Also, the sample collection period ( 8 months) of our study is another limitation.

\section{Conclusion}

It is not clear why the dominance of G9 is persistent in the absence of widespread vaccine use in Turkey. Our phylogenetic analysis showed that G9 strains of two new lineages were circulating in Ankara. We assume that these strains of genotype G9 infected the immunologically naïve population and, as a result, spread rapidly and increased the proportion of G9 strains.

We found that RV G9P[8] strains increased considerably in Ankara in 2012. This increase might be due to introduction of a new dominant strain of G9 in the population. We believe this information is important for policy-makers before the implementation of a national RV immunization program in Turkey.

\section{Acknowledgements}

This research received no specific Grant from any funding agency in the public, commercial, or not-for-profit sectors.

\section{Conflicts of interest}

The authors declare that there is no conflict of interests.

\section{Authors' contribution}

AAK, investigation, writing original draft preparation, visualization; MA, investigation, writing original draft preparation; TM, investigation, data analysis; TY, investigation; BD, resources; GB and KA, methodology, writing-review and editing, supervision.

\section{References}

1. Lanata CF, Fischer-Walker CL, Olascoaga AC, Torres CX, Aryee MJ, Black RE, et al. Global causes of diarrheal disease mortality in children $<5$ years of age: a systmeatic review. PLoS One 2013; 8: e72788. DOI: 10.1371/journal.pone.0072788

2. Zheng S, Yu F, Chen X, Cui D, Cheng Y, Xie G, et al. Enteropathogens in children less than 5 years of age with acute diarrhea: a 5-year surveillance study in the Southeast Coast of China. BMC Infect Dis 2016; 16: 434. DOI: 10.1186/s12879-016-1760-3

3. Koksal T, Akelma AZ, Koksal AO, Kutukoglu I, Ozdemir O, Yuksel CN, et al. Cost-effectiveness of rotavirus vaccination in Turkey. J Microbiol Immunol Infect 2017; 50: 693-9. DOI: 10.1016/j.jmii.2016.03.005

4. Tate JE, Burton AH, Boschi-Pinto C, Parashar UD. Global, Regional, and National Estimates of Rotavirus Mortality in Children < 5 Years of Age, 2000-2013. Clin Infect Dis. 2016; 62(suppl 2): S96-S105. DOI: 10.1093/ cid/civ1013

5. WHO. Estimated rotavirus deaths for children under 5 years of age: 2013, 215 000. Immunization, Vaccines and Biologicals: Monitoring and surveillance. Available at: https://www.who.int/immunization/monitoring_surveillance/burden/estimates/rotavirus/en/. Accessed January 27, 2019.

6. Crawford SE, Ramani S, Tate JE, Parashar UD, Svensson L, Hagbom M, et al. Rotavirus infection. Nat Rev Dis Primers. 2017; 9(3): 17083. DOI: 10.1038/ nrdp. 2017.83

7. Shepherd FK, Herrera-Ibata DM, Porter E, Homwong N, Hesse R, Bai J, et al. Whole Genome Classification and Phylogenetic Analyses of Rotavirus B strains from the United States. Pathogens 2018; 7(2): 44. DOI: 10.3390/pathogens 7020044

8. Laboratory of Viral Genomics. Rotavirus Classification Working Group (RCWG), Virus Classification. Available at: https://rega.kuleuven.be/cev/viralmetagenomics/virus-classification/rcwg (List of accepted genotypes).

9. Owor BE, Mwanga MJ, Njeru R, Mugo R, Ngama M, Otieno GP, et al. Molecular characterization of rotavi- 
rus group A strains circulating prior to vaccine introduction in rural coastal Kenya, 2002-2013. Wellcome Open Research 2018; 3: 150. DOI: 10.12688/wellcomeopenres. 14908.1

10. Chen SC, Tan LB, Huang LM, Chen KT. Rotavirus infection and the current status of rotavirus vaccines. J Formos Med Assoc 2012; 111: 183-93. DOI: 10.1016/j. jfma.2011.09.024

11. Bozdayi G, Altay A, Yahiro T, Ahmed S, Meral M, Dogan B, et al. Re-emergence of genotype G9 during a five-and-a-half-year period in Turkish children with rotavirus diarrhea. Arch Virol 2016; 161: 2879-84. DOI: 10.1007/s00705-016-2986-5

12. Tapisiz A, Karahan ZC, Çiftçi E, Ince E, Doğru U. Changing patterns of rotavirus genotypes in Turkey. Curr Microbiol 2011; 63: 517-22. DOI: 10.1007/ s00284-011-0014-2

13. Cataloluk O, Iturriza M, Gray J. Molecular characterization of rotaviruses circulating in the population in Turkey. Epidemiol Infect 2005; 133: 673-8. DOI: 10.1017/S0950268805003882

14. Bozdayi G, Dogan B, Dalgic B, Bostanci I, Sari S, Battaloglu NO, et al. Diversity of human rotavirus G9 among children in Turkey. J Med Virol 2008; 80: 73340. DOI: $10.1002 / j m v .21120$

15. Durmaz R, Kalaycioglu AT, Acar S, Bakkaloglu Z, Karagoz A, Korukluoglu G, et al. Prevalence of rotavirus genotypes in children younger than 5 years of age before the introduction of a universal rotavirus vaccination program: report of rotavirus surveillance in Turkey. PLoS One 2014; 9: e113674. DOI: 10.1371/journal. pone. 0113674

16. Gentsch JR, Glass RI, Woods P, Gouvea V, Gorziglia $\mathrm{M}$, Flores $\mathrm{J}$, et al. Identification of group A rotavirus gene 4 types by polymerase chain reaction. J Clin Microbiol 1992; 30: 1365-73.

17. Gouvea V, Glass RI, Woods P, Taniguchi K, Clark HF, Forrester B, et al. Polymerase chain reaction amplification and typing of rotavirus nucleic acid from stool specimens. J Clin Microbiol 1990; 28: 276-82.

18. Gunasena S, Nakagomi O, Isegawa Y, Kaga E, Nakagomi T, Steele AD, et al. Relative frequency of VP4 gene alleles among human rotaviruses recovered over a 10-year period (1982-1991) from Japanese children with diarrhea. J Clin Microbiol 1993; 31: 2195-7.

19. Uchida R, Pandey BD, Sherchand JB, Ahmed K, Yokoo M, Nakagomi T, et al. Molecular epidemology of rotavirus diarrhea among children and adults in $\mathrm{Ne}$ pal: detection of G12 strains with $\mathrm{P}[6]$ or $\mathrm{P}[8]$ and a G11P[25] strain. J Clin Microbiol 2006; 44: 3499-505. DOI: 10.1128/JCM.01089-06

20. Iturriza-Gomara M, Kang G, Gray J. Rotavirus genotyping: keeping up with an evolving population of human rotaviruses. J Clin Virol 2004; 31(4): 259-65. DOI: 10.1016/j.jcv.2004.04.009

21. Hall TA. "BioEdit: a user-friendly biological sequence alignment editor and analysis program for Windows 95/98/NT'. Nucl. Acids. Symp. Ser. 1999; 41: 95-98.

22. Tamura K, Stecher G, Peterson D, Filipski A, Kumar S. MEGA6: Molecular Evolutionary Genetics Analysis version 6.0. Mol Biol Evol 2013; 30: 2725-9. DOI: 10.1093/molbev/mst197

23. Abdel-Haq N, Amjad M, McGrath E, Salimnia H, Fairfax M, Asmar BI. Rotavirus infections in Detroit, USA, a region of low vaccine prevalence. Virus disease 2016; 27: 179-82. DOI: 10.1007/s13337-016-0309-9

24. Ceyhan M, Alhan E, Salman N, Kurugol Z, Yildirim I, Celik U, et al. Multicenter prospective study on the burden of rotavirus gastroenteritis in Turkey, 2005-2006: a hospital-based study. J Infect Dis 2009; 200: 234-8. DOI: $10.1086 / 605056$

25. Abdel-Haq N, Amjad M, McGrath E, Chearskul P, Amer A, Salimnia H, et al. Emergence of human rotavirus genotype G9 in metropolitan Detroit between 2007 and 2009. J Med Microbiol 2011; 60: 761-7. DOI: 10.1099/jmm.0.026807-0

26. Esteban LE, Rota RP, Gentsch JR, Jiang B, Esona M, Glass RI, et al. Molecular epidemiology of group A rotavirus in Buenos Aires, Argentina 2004-2007: reemergence of G2P[4] and emergence of G9P[8] strains. J Med Virol 2010; 82: 1083-93. DOI: 10.1002/jmv.21745

27. Midgley S, Böttiger B, Jensen TG, Friis-Møller A, Person LK, Nielsen L, et al. Human group A rotavirus infections in children in Denmark: detection of reassortant G9 strains and zoonotic P[14] strains. Infect Genet Evol 2014; 27: 114-20. DOI: 10.1016/j.meegid.2014.07.008

28. Wangchuk S, Mitui MT, Tshering K, Yahiro T, Bandhari $\mathrm{P}$, Zangmo $\mathrm{S}$, et al. Dominance of emerging G9 and G12 genotypes and polymorphism of VP7 and VP4 of rotaviruses from Bhutanese children with severe diarrhea prior to the introduction of vaccine. PLoS One 2014; 9: e110795. DOI: 10.1371/journal.pone.0110795

29. Dulgheroff AC, Figueiredo EF, Gouvêa VS, Domingues AL. Changes in epidemiology of rotavirus in the Triân- 
gulo Mineiro region of Brazil: lack of two consecutive rotavirus seasons. Braz J Med Biol Res 2014; 47: 10915. DOI: 10.1590/1414-431X20144156

30. Mukhopadhya I, Murdoch H, Berry S, Hunt A, Iturriza-Gomara $M$, Smith-Palmer $A$, et al. Changing molecular epidemiology of rotavirus infection after introduction of monovalent rotavirus vaccination in Scotland. Vaccine 2017; 35: 156-63. DOI: 10.1016/j. vaccine.2016.11.028

31. Öztas S, Altındis M, Asik G, Acar S, Karagöz A, Bükülmez A, et al. Rotavirus and adenovirus in children with acute gastroenteritis and the molecular epidemiology of rotavirus. Nobel Med 2016; 12: 87-93.

32. Justino MCA, Araujo EC, van Doorn L-J, Oliveira CS, Gabbay YB, Mascarenhas JDP, et al. Oral live attenuated human rotavirus vaccine (RotarixTM) offers sustained high protection against severe G9P [8] rotavirus gastroenteritis during the first two years of life in Brazilian children. Mem Inst Oswaldo Cruz, Riode Janeiro 2012; 107(7): 846-53. DOI: 10.1590/S007402762012000700002

33. Kahraman H, Altay-Kocak A, Albakkour K, Muftah $\mathrm{H}$, Dalgic B, Caglar K, et al. Emerging rotavirus genotypes $\mathrm{G} 10$ and $\mathrm{G} 12$ in patients with acute gastroenteritis in Turkey. 21st ESCV Annual Meeting, Athens, 23-26 September, 2018, Poster No: 273.

34. Durmaz R, Bakkaloglu Z, Unaldi O, Karagoz A, Korukluoglu G, Kalaycioglu AT, et al. Prevalence and diversity of rotavirus A genotypes circulating in Turkey during a 2-year sentinel surveillance period, 20142016. J Med Virol. 2018; 90: 229-38. DOI: 10.1002/ jmv. 24945 